\title{
Anthocyanins in wheat grain: genetic control, health benefit and bread-making quality
} \author{
T.G. Amstislavskaya ${ }^{4}$ \\ 'N.I. Vavilov All-Russian Research Institute of Plant Genetic Resources (VIR), St. Petersburg, Russia \\ ${ }^{2}$ Institute of Cytology and Genetics, SB RAS, Novosibirsk, Russia \\ ${ }^{3}$ Novosibirsk State University, Novosibirsk, Russia \\ ${ }^{4}$ Scientific Research Institute of Physiology and Basic Medicine, Novosibirsk, Russia
}

E.K. Khlestkina ${ }^{1,2 *}$, O.Y. Shoeva ${ }^{2}$, E.I. Gordeeva ${ }^{2}$, Y.S. Otmakhova ${ }^{3}$, N.I. Usenko ${ }^{3}$, M.A. Tikhonova ${ }^{2,4}$, M.V. Tenditnik ${ }^{4}$,

DOI 10.18699/ICG-PlantGen2019-02

๑) Autors, 2019

*e-mail:khlest@bionet.nsc.ru

\begin{abstract}
Anthocyanins are plant secondary metabolites having multiple biological functions. In this paper, we summarize data on anthocyanins in wheat grain, including molecular-genetic mechanisms underlying the synthesis of anthocyanins in the grain pericarp, the effect of anthocyanins on bread-making quality and health benefit. Anthocyanin synthesis in wheat pericarp tissue is controlled by two complementary genes, Pp3/TaMyc1 and Pp-1, mapped to chromosome 2A and homologous group 7 chromosomes, respectively. These genes encode transcription factors with the bHLH and R2R3-MYB-regulatory domains, respectively, which activate expression of the anthocyanin biosynthesis structural genes, encoding enzymes of the pathway, in a tissue-specific manner. A comprehensive study of the effect of wheat genes associated with the level of anthocyanins in grain on the preventive effect of grain products in neurodegenerative disorders was carried out. The use of near-isogenic lines (NILs) having almost similar genomes with the exception of a small part of chromosome $2 \mathrm{~A}$, which contains $P p 3$, has allowed relating the observed differences precisely with anthocyanin biosynthesis. As a result, it was revealed that the $P p 3$ gene is related to the production of dietary products preventing neurodegenerative changes caused by Alzheimer's and Parkinson's diseases and natural aging. The beneficial effect of a grain diet with a high content of anthocyanins on the working memory and molecular processes of neuroregeneration was shown on mice. The use of the same wheat NILs for testing bread-making quality showed the resistance of anthocyanins to the backing process and a better quality and organoleptic properties of bakery products made from anthocyanin-rich grains in comparison with products obtained from control grains. An optimal scheme for the accelerated creation of wheat breeding lines with a high content of anthocyanins in the grain pericarp is considered.

Key words: structural genes; regulatory genes; purple pericarp; blue aleurone; biological activity; breeding; flour confectionery products; whole-grained bread.
\end{abstract}

\section{Introduction}

Anthocyanins are plant secondary metabolites, which are synthesized in different parts of plants, including cereal plants endosperm, aleurone, seed coat and pericarp (Ficco et al., 2014; Khlestkina et al., 2015). They are responsible for the diversity of colors observed in the nature. Besides the well-recognized role in the attraction of pollinators and seed dispersals, they participate in plant protection against adverse environmental factors, as well as in signaling (Landi et al., 2015). Anthocyanins are widespread in angiosperms and occur in some gymnosperms, while they are absent from other taxa of plants that nevertheless contain colorless intermediates preceding anthocyanins. These pigments are the last to have appeared during land plant evolution (Rausher, 2006).

Both human and animal studies considering the main anthocyanins of berries demonstrated that these compounds have wide biological activities important for human health maintenance (Tsuda, 2012). Unlike berries, bread is a daily consumption food and enriching bakery products with such high nutritional value compounds as anthocyanins is reasonable. In respect to that, there is interest in data on different aspects of wheat grain anthocyanins, including genetic control of their biosynthesis, health benefit and bread-making quality.

\section{Regulation of anthocyanin biosynthesis in wheat pericarp}

Anthocyanins belong to flavonoid compounds with a common 15-carbon skeleton C6-C3-C6 consisting of two phenyl rings $(\mathrm{A}$ and $\mathrm{B})$ and a heterocyclic ring $(\mathrm{C})$. Different modifications of these rings determine the whole diversity of flavonoids that count more than 500 individual compounds (Andersen, Jordheim, 2006). Anthocyanins differ from the other flavonoids by a positive charge and a double bond present in C-ring. They are derived in course of the general phenylpropanoid and anthocyanin branch of the flavonoid biosynthesis pathways (Winkel-Shirley, 2001). At the first stage of synthesis, phenylalanine is converted, in a stepwise manner, by phenylalanine ammonia-lyase (PAL), cinnamate 4-hydroxylase $(\mathrm{C} 4 \mathrm{H})$ and 4-coumarate CoA ligase (4CL) into 4-coumaroyl-CoA. Then chalcone synthase (CHS), chalcone isomerase (CHI), flavanone hydroxylase $(\mathrm{F} 3 \mathrm{H})$, flavonoid 3'-hydroxylase (F3'H), flavonoid 3', 5'-hydroxylase (F3'5'H), dihydroflavonol 4-re- 
ductase (DFR) and anthocyanidin synthase (ANS) transform 4-coumaroyl-CoA to anthocyanidins, which are finally modified by diverse transferases to individual anthocyanins. Tissue specific accumulation of anthocyanins is controlled by regulatory genes encoding transcription factors with the bHLH, R2R3-MYB regulatory domains and WD40 repeats, which are combined into the MYB-bHLH-WD40 (MBW) complex and activate transcription of the structural genes encoding enzymes of the biosynthesis.

In wheat grain, anthocyanins can be accumulated in pericarp and aleurone tissues. The most abundant anthocyanin in purple wheat is cyanidin 3-glucoside, while in blue one, it is delphinidin 3-glucoside (Abdel-Aal et al., 2006). The key structural genes were cloned in wheat unlike the genes for enzymes of final modifications that are represented by wide gene families and their identification is therefore hampered (Shoeva, Khlestkina, 2015). Two complementary genes Pp3/ $T a M y c l$ and $P p-1$ control anthocyanin synthesis in the wheat pericarp. $P p 3$ (mapped to chromosome 2A) encodes a bHLH transcription factor (Shoeva et al., 2014). The $P p-1$ genes (7A, 7B, 7D) encode R2R3-MYB-type transcription factors (Jiang et al., 2018). The $B a$ genes responsible for blue aleurone were transferred into cultivated wheat varieties from distant relatives such as Thinopyrum ponticum, Th. bessarabicum, T. boeoticum and T. monococcum (Zeven, 1991). The wheat grass ThMYC4E gene encoding the regulatory factor with the bHLH domain was identified as a candidate gene for $\mathrm{Bal}(\mathrm{Li}$ et al., 2017).

\section{Health benefit}

Anthocyanins consumed with food may have positive effects on human health. Due to suppression of genes involved in fatty acid synthesis and inhibition of pancreatic amylase and intestinal $\alpha$-glucosidase, anthocyanins may have a hypoglycemic effect (Tsuda et al., 2003; Tadera et al., 2006; Shobana et al., 2009). Anthocyanins and other flavonoids may be useful for the prevention of a variety of pathologies, including cardiovascular diseases (Howard, Kritchevsky, 1997; Lila, 2004). They demonstrate wide biological activities ranging from antioxidation, anti-inflammatory, anti-cancer, anti-ageing effects to lipid-profile regulation, obesity and diabetes prevention, hyperglycemia and retinal protections (Tsuda, 2012).

Some comparative studies were carried out to reveal effects of anthocyanin-rich wheat grain as a feed additive on growth characteristics of economically important animals. Inclusion of purple grains of a breeding line in the feed compound for high-yielding laying hens was demonstrated to improve lay-up parameters such as line egg weight, laying per hen and reduce feed compound consumption per unit of production. The yolk color of eggs laid by hens was not affected by the color of the grains eaten (Ruckschloss et al., 2010).

Feeding tests performed on fingerling carp showed the positive impact of purple grain of the wheat cultivar 'Konini' on the mass and length of carps compared with the control (Mareš et al., 2015).

The influence of wheat anthocyanins on antioxidant activity and liver functions was estimated in rats, chickens and fish (Mrkvicová et al., 2017). Significantly higher values of anti- oxidant status were determined in the liver of rats fed purple grains. The chickens fed 'Konini' wheat showed significantly different values obtained by distinct methods for antioxidant status measurement. No significant differences were detected in the hepatopancreases of fish. Animals fed 'Konini' wheat showed a tendency to lower liver enzyme activities in general, but a significant difference was found only in gamma-glutamyl transferase activity in the chicken's blood. The results suggested that feeding anthocyanin-rich grain can improve antioxidant activity and functions of liver tissue.

A comprehensive study of the effect of wheat genes associated with the level of anthocyanins in grain on the preventive effect of grain products in neurodegenerative disorders was carried out. The use of NILs having almost similar genomes with the exception of a small part of chromosome $2 \mathrm{~A}$, which contains the $P p 3$ gene, has allowed relating the observed differences precisely with anthocyanin biosynthesis (Shoeva et al., 2014; Gordeeva et al., 2015). Using mice as a model for neurodegenerative changes caused by Alzheimer's and Parkinson's diseases and natural aging, we revealed a beneficial effect of a grain diet with a high content of anthocyanins on the working memory and molecular processes of neuroregeneration (Tenditnik et al., 2017).

\section{Bread-making quality}

Anthocyanin-rich bakery products are, first of all, the products obtained from bran or with the addition of bran. The grains of the above-mentioned wheat NILs differing in anthocyanin content in the pericarp were used for evaluation of anthocyanin content in the end-use product, as well as in mixtures of flour and bran used for baking and separately in the bran (Khlestkina et al., 2017). As a result, significant differences were detected in samples obtained from anthocyanin-rich grains, compared with the control including the products that had passed a full processing cycle. The extraction of anthocyanins in the conditions most similar to those in the stomach has allowed assessing the amount of assimilable anthocyanins. The estimations have shown that one can get up to $1.03 \mathrm{mg}$ of anthocyanins with $100 \mathrm{~g}$ of whole-grained bread produced from anthocyanin-rich wheat (Khlestkina et al., 2017). It was shown that bread-making quality and the organoleptic properties of bakery products made from anthocyanin-rich grains did not concede, or in some cases were higher than the corresponding properties of products obtained from control NIL grains. In addition, it was found that the presence of anthocyanin increases the shelf life of bakery products and their resistance to molding in provocative conditions (Khlestkina et al., 2017).

Later, flour and wheat bran with anthocyanins and the control group were used for the production of flour confectionery products (Usenko et al., 2018). The share of anthocyanins in the products obtained from anthocyanin-rich wheat was 2.52.6 times higher than that in similar products obtained from control grains. The differences revealed between the grains of anthocyanin-rich and control wheat in the end-use products testify to the resistance of anthocyanins to technological processing. It has been estimated that when eating 100 grams of biscuit made from flour with the addition of anthocyanin-rich 
bran, the consumption of these beneficial substances will be up to $0.83 \mathrm{mg}$. Thus, a high content of anthocyanins in wheat bran allows producing enriched confectionery products with a high nutritional value (Usenko et al., 2018).

\section{Marker-assisted breeding}

Using DNA-markers for the $P p$ genes (Shoeva et al., 2014; Zong et al., 2017), we developed purple-grained breeding lines by crossing donor line producing anthocyanins in grain with elite wheat cultivars. The development of the breeding lines took 2 years (6 generations, including that in greenhouses) and required application of the DNA-markers twice. The markers linked to $P p-1$ and $P p 3$ were used first to select homozygouse plants carrying dominant alleles of these genes in $\mathrm{F}_{2}$ generation. After three backcrosses of the selected plats to the parental cultivars, the resulted final purple-grained breeding lines homozygous to the markers linked to $P p-1$ and $P p 3$ were selected among $\mathrm{BC}_{3} \mathrm{~F}_{2-3}$ progenies. The lines obtained according to this scheme are already used in field trials. Earlier, the marker-assisted backcrossing approach was used to develop a set of NILs carrying different combinations of the $P p$ alleles. The volume of plant material was reduced two-fold and the planting area was decreased $\sim 70$-fold due to the application of DNA-markers (Gordeeva et al., 2015).

\section{Conclusions}

The results of evaluation of end-use quality products combined with the data about the beneficial health effects of anthocyanins form wheat grain suggest that wheat bakery and confectionery products made from anthocyanin-rich grains can be included to the list for dietary food. In order to accelerate the breeding of wheat for dietary purposes, we have used data on molecular-genetic mechanisms underlying anthocyanin synthesis in the wheat pericarp and developed an optimal scheme for the accelerated creation of breeding lines needed for further selection and registration of anthocyaninrich wheat varieties.

\section{References}

Abdel-Aal E.S.M., Young J.C., Rabalski I. Anthocyanin composition in black, blue, pink, purple, and red cereal grains. J. Agri. Food Chem. 2006;54(13):4696-4704. DOI 10.1021/jf0606609.

Andersen O.M., Jordheim M. The anthocyanins. In: Andersen O.M., Markham K.R. (Eds). Flavonoids: Chemistry, Biochemistry and Applications. 2006. Boca Raton, FL: CRC Press. P. 452-471. DOI 10.1201/9781420039443.ch10.

Ficco D.B., De Simone V., Colecchia S.A., Pecorella I., Platani C., Nigro F., De Vita P. Genetic variability in anthocyanin composition and nutritional properties of blue, purple, and red bread (Triticum aestivum L.) and durum (Triticum turgidum L. ssp. turgidum convar. durum) wheats. J. Agri. Food Chem. 2014;62(34):8686-8695. DOI $10.1021 / \mathrm{jf5} 503683$.

Gordeeva E.I., Shoeva O.Y., Khlestkina E.K. Marker-assisted development of bread wheat near-isogenic lines carrying various combinations of purple pericarp (Pp) alleles. Euphytica. 2015;203(2): 469-476. DOI 10.1007/s10681-014-1317-8.

Howard B.V., Kritchevsky D. Phytochemicals and cardiovascular disease a statement for healthcare professionals from the American heart association. Circulation. 1997;95(11):2591-2593. DOI 10.1161/01.CIR.95.11.2591.
Jiang W., Liu T., Nan W., Jeewani D.C., Niu Y., Li C., Wang Y., Shi X., Wang C., Wang J., Li Y., Gao X., Wang Z. Two transcription factors TaPpm1 and TaPpb1 co-regulate anthocyanin biosynthesis in purple pericarps of wheat. J Exp Botany. 2018;69(10):2555-2567. DOI 10.1093/jxb/ery 101.

Khlestkina E.K., Shoeva O.Y., Gordeeva E.I. Flavonoid biosynthesis genes in wheat. Russ J Genet Appl Res. 2015;5(3):268-278. DOI 10.1134/S2079059715030077.

Khlestkina E.K., Usenko N.I., Gordeeva E.I., Stabrovskaya O.I., Sharfunova I.B., Otmakhova Y.S. Evaluation of wheat products with high flavonoid content: justification of importance of marker-assisted development and production of flavonoid-rich wheat cultivars. Vavilov J. Genet. Breed. 2017;21(5):545-553. DOI 10.18699/VJ17.25-o.

Landi M., Tattini M. Gould K.S. Multiple functional roles of anthocyanins in plant-environment interactions. Environ. Exp. Bot. 2015; 119:4-17. DOI 10.1016/j.envexpbot.2015.05.012.

Li N., Li S., Zhang K., Chen W., Zhang B., Wang D., Zhang H. ThMYC4E, candidate Blue aleurone 1 gene controlling the associated trait in Triticum aestivum. PloS ONE. 2017;12(7):e0181116. DOI 10.1371/journal.pone.0181116.

Lila M.A. Anthocyanins and human health: an in vitro investigative approach. J. Biomed. Biotechnol. 2004;2004(5):306-313. DOI 10.1155/S111072430440401X.

Mareš J., Brabec T., Vyhnánek T., Trojan V., Štiasna K., Presinszká M., Mrkvicová E., Hřivna L., Havel L. The effect of feeding wheat with purple pericarp on the growth of carp. Potravinarstvo. 2015;9(1):262-267. DOI 10.5219/477.

Mrkvicová E., Pavlata L., Karásek F., Št’astník O., Doležalová E., Trojan V., Brabec T. The influence of feeding purple wheat with higher content of anthocyanins on antioxidant status and selected enzyme activity of animals. Acta Veterinaria Brno. 2017;85(4):371-376. DOI 10.2754/avb201685040371.

Tadera K., Minami Y., Takamatsu K., Matsuoka T. Inhibition of $\alpha$-glucosidase and $\alpha$-amylase by flavonoids. J. Nutr. Sci. Vitaminol. 2006; 52(2):149-153. DOI 10.3177/jnsv.52.149.

Tenditnik M.V., Tikhonova M.A., Pavlov K.S., Amstislavskaya T.G., Khlestkina E.K. Evaluating the neuroprotective potential of wheat grain with high antocyanin content in correction of behavioral deficits induced by amyloid-beta neuro toxicity in mice. Abstracts of Belyaev Conference, 1-7August 2017, Novosibirsk. P. 165.

Tsuda T., Horio F., Uchida K., Aoki H., Osawa T. Dietary cyaniding 3-O- $\beta$-D-glucoside-rich purple corn color prevents obesity and ameliorates hyperglycemia in mice. J. Nutr. 2003;133(7):2125-2130. DOI 10.1093/jn/133.7.2125.

Tsuda T. Dietary anthocyanin-rich plants: biochemical basis and recent progress in health benefits studies. Mol. Nutr. Food Res. 2012; 56(1):159-170. DOI 10.1002/mnfr.201100526.

Rausher M.D. The evolution of flavonoids and their genes. In: Grotewold E. (Ed.). The Science of Flavonoids. 2006;175-211, Springer, New York, NY.

Ruckschloss L., Matúšková K., Hanková A., Jančík D. Influence of winter wheat with purple colour of the corn on laying hens' efficiency and eggs quality. Potranivarstvo. 2010:4(Suppl.):231-235.

Shobana S., Sreerama Y.N., Malleshi N.G. Composition and enzyme inhibitory properties of finger millet (Eleusine coracana L.) seed coat phenolics: Mode of inhibition of $\alpha$-glucosidase and pancreatic amylase. Food Chem. 2009;115(4):1268-1273. DOI 10.1016/j.foodchem.2009.01.042

Shoeva O., Gordeeva E., Khlestkina E. The regulation of anthocyanin synthesis in the wheat pericarp. Molecules. 2014;19(12):2026620279. DOI 10.3390/molecules191220266.

Shoeva O.Y., Khlestkina E.K. The specific features of anthocyanin biosynthesis regulation in wheat. Ogihara Y., Takumi S., Handa H. (Eds.). Advances in Wheat Fenetics: from Genome to Field. Japan: Springer, 2015. P. 147-157. DOI 10.1007/978-4-431-55675-6 16. 
Tsuda T. Dietary anthocyanin-rich plants: biochemical basis and recent progress in health benefits studies. Molecular Nutrition Food Res. 2012;56(1):159-170. doi.org/10.1002/mnfr.201100526.

Usenko N.I., Khlestkina E.K., Asavasanti S., Gordeeva E.I., Yudina R.S., Otmakhova Y.S. Possibilities of Enriching Food Products with Anthocyanins by Using New Forms of Cereals. Foods Raw Materials. 2018;6(1):128-135. DOI 10.21603/2308-4057-2018-1128-135.

Winkel-Shirley B. Flavonoid biosynthesis. A colorful model for genetics, biochemistry, cell biology and biotechnology. Plant Physiol. 2001;126:485-493. DOI 10.1104/pp.126.2.485.
Zeven A.C. Wheats with purple and blue grains: a review. Euphytica. 1991;56(3):243-258.

Zong Y., Xi X., Li S., Chen W., Zhang B., Liu D., Zhang H. Allelic variation and transcriptional isoforms of wheat TaMYC1 gene regulating anthocyanin synthesis in pericarp. Front. Plant Sci. 2017;8:1645. DOI 10.3389/fpls.2017.01645.

Acknowledgements. The study is supported by the Russian Science Foundation (Project No. 16-14-00086).

Conflict of interest. The authors declare no conflict of interest. 